\title{
Новый тип оптического сенсора в структуре кремний на изоляторе
}

\author{
A.B. Царев ${ }^{1,2}$ \\ ${ }^{1}$ Институт физики полупроводников им. А. В. Ржанова СО РАН, г. Новосибирск, \\ 630090, просп. Академика Лаврентьева, 13 \\ ${ }^{2}$ Новосибирский государственный университет, г. Новосибирск, \\ 630090,, ул. Пирогова, 2 \\ тел: +79134810 578, факс:+7(383)333-2771, эл.nочта: tsarev@isp.nsc.ru
}

DOI 10.34077/RCSP2021-63

В данной работе представлены результаты [1] численного моделирования модифицированной конструкции оптического сенсора на основе сегментированной периодической решетки оксинитрида кремния $(\mathrm{SiON})$, расположенного над кремниевым волноводом (кремниевой проволоки) в структуре кремний на изоляторе (КНИ). Решетка отделена от волновода тонким окисным слоем, обеспечивающего эффективную туннельную связь их оптических полей. Данная сегментированная решетка работает как вытекающий волновод, который фильтрует входную мощность от широкополосного оптического источника и излучает ее в виде выходящего оптического пучка, содержащего спектральные компоненты в узком диапазоне длин волн, а также обладающих небольшой угловой расходимостью. Угол излучения сильно зависит от показателя преломления окружающей сенсор среды. Это дет возможность проводить считывания данных с данного интегрально-оптического сенсора путем измерения картины дальнего поля в фокальной плоскости объектива, который расположен рядом с сенсорным элементом. Концепция работы данного типа оптического сенсора была проверена [1] прямым численным моделированием с помощью метода конечных разностей во временной области (FDTD) с использованием оптического пакета от Rsoft [2]. Датчик продемонстрировал умеренный собственный предел обнаружения (iLOD) $\approx 0,004 \mathrm{RIU}$ при потенциале увеличения iLOD до 0,001 RIU в случае применении длинных структур порядка 10 мм.

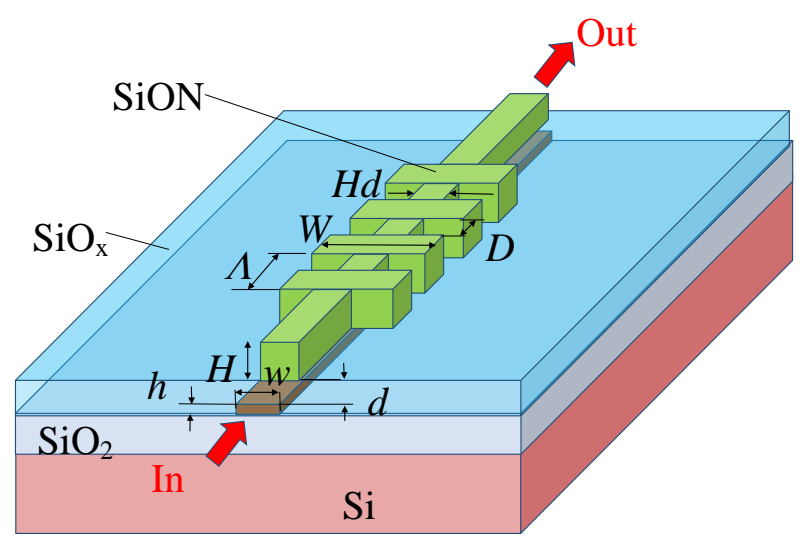

a)

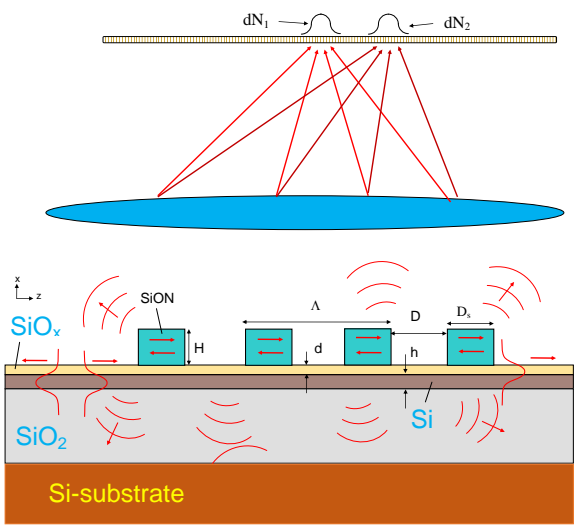

б)

Рис. 1. Новый тип оптического сенсора на основе считывания данных путем анализа дифракционной картины в дальнем поле [1]. а) схематичное изображение сенсорного элемента; б) принципиальная схема считывания данных сенсора с помощью матричного фотоприемника, расположенного в фокальной плоскости оптической линзы.

\section{Литература}

[1] A. Tsarev, et al // Sensors, 2020. V. 20, P.5306

[2] Rsoft by SYNOPSYS (https://optics.synopsys.com/rsoft/), single license (2020). 